\title{
Prevalence and prognostic value of plasma glucose abnormalities among full-term and late-preterm neonates with sepsis
}

\author{
Muhammad Said El-Mekkawy ${ }^{*}$ (D) and Dalia Monir Ellahony
}

\begin{abstract}
Background: Neonatal sepsis is occasionally associated with abnormal plasma glucose level, but data in full-term and late-preterm neonates is limited. Our aim was to determine prevalence and prognostic value of plasma glucose abnormalities among these patients.

Results: We conducted a prospective observational study of 174 full-term and late-preterm neonates with cultureproven or possible sepsis. Plasma glucose level was measured upon neonatal intensive care unit (NICU) admission. The primary outcome was NICU mortality. Hyperglycemia occurred in 12.6\%, while hypoglycemia occurred in 10.9\% of infants with sepsis. The mortality rate was $36.4 \%, 47.4 \%$, and $16.5 \%$ among infants with hyperglycemia, hypoglycemia, and normoglycemia respectively $(P=0.002)$. Both hyperglycemia and hypoglycemia were independent predictors of mortality [adjusted $\mathrm{OR}$ and $95 \% \mathrm{Cl}=2.89(1.03-8.13)$ and $3.86(1.32-11.26)$ respectively]. Mechanical ventilation rate was higher among the hypoglycemia subgroup compared with both the hyperglycemia and normoglycemia subgroups $(P=$ 0.046), but glycemic status was not associated with the length of NICU stay. Hypoglycemia was also associated with a lower platelet count $(P=0.015)$.
\end{abstract}

Conclusion: Plasma glucose abnormalities are not uncommon in neonatal sepsis. Both hypoglycemia and hyperglycemia could be utilized for mortality prediction. Besides, hypoglycemia was associated with a higher mechanical ventilation rate. However, these associations might not be causal.

Keywords: Hyperglycemia, Hypoglycemia, Plasma glucose, Neonatal sepsis, Mortality

\section{Background}

Neonatal sepsis is a major health problem associated with significant morbidity and mortality [1]. Blood glucose abnormalities, including hypoglycemia [2] and hyperglycemia [3], are not uncommon in neonatal sepsis.

Hypoglycemia can manifest with poor feeding, hypotonia, apnea, jitteriness, coma, and seizures [4]. Neonatal hypoglycemia has the potential to inflict devastating injuries on the developing brain since glucose is the primary fuel normally utilized by that organ. This might contribute to the pathogenesis of long-term neurological disorders such as cerebral palsy, mental retardation, blindness, and intractable epilepsy [5, 6].

\footnotetext{
* Correspondence: mekkawy55@gmail.com

Department of Pediatrics, Faculty of Medicine, Menoufia University, Shebeen El-Kom 32511, Egypt
}

(c) The Author(s). 2019 Open Access This article is distributed under the terms of the Creative Commons Attribution 4.0 International License (http://creativecommons.org/licenses/by/4.0/), which permits unrestricted use, distribution, and reproduction in any medium, provided you give appropriate credit to the original author(s) and the source, provide a link to the Creative Commons license, and indicate if changes were made. glycemia are less dramatic and include glucosuria and osmotic diuresis but these can progress to dehydration, fever, ketosis, and metabolic acidosis [7].

Sepsis and other neonatal stressful conditions might trigger hyperglycemia, most likely through an increase in the levels of counter-regulatory hormones like cortisol, adrenaline, and glucagon, with a consequent stimulation of glycogenolysis and gluconeogenesis as well as interference with insulin release and sensitivity [7].

Low birth weight infants are, in particular, more likely to suffer from deficiency of insulin or peripheral resistance to its actions $[8,9]$. Furthermore, inotropes, corticosteroids, and lipid emulsions put the infant at a greater risk $[10,11]$.

Hyperglycemia was found to be associated with neonatal mortality [12]. It was also shown to be a risk factor for severe intraventricular hemorrhage [13] and retinopathy of prematurity [14]. However, previous studies

\section{Springer Open}


predominantly included very premature infants with or without sepsis. The aim of the present study was to assess the prevalence and prognostic value of plasma glucose abnormalities, specifically, among full-term and late-preterm neonates with sepsis.

\section{Materials and methods}

\section{Study design}

This was a prospective observational study conducted in the neonatal intensive care unit (NICU) of Menoufia University Hospital from January 2017 to July 2018. The study protocol was approved by the Menoufia Faculty of Medicine Committee for Medical Research Ethics.

\section{Study population}

"Full-term" and "late-preterm" neonates with "early onset" (within 72 hours of birth) or "late onset" sepsis were consecutively enrolled after obtaining informed parental consent. Infants with either "proven" or "possible" sepsis were included in the study. "Proven sepsis" was diagnosed when the baby had clinical signs compatible with sepsis in association with a positive blood, cerebrospinal fluid (CSF), or urine culture [15]. "Possible sepsis" was diagnosed in the presence of clinical manifestations of sepsis in addition to elevated C-reactive protein $(\mathrm{CRP})>5 \mathrm{mg} / \mathrm{dL}$ [16].

The exclusion criteria included (1) infants beyond 1 month of age, (2) sepsis complicating another neonatal illness such as infant of diabetic mother and perinatal asphyxia, (3) gestational age < 34 weeks, (4) failure to measure plasma glucose level within $1 \mathrm{~h}$ of NICU admission, and (5) infants with an initial diagnosis of possible sepsis who were later found to have another diagnosis like inborn errors of metabolism.

\section{Clinical and laboratory evaluation}

For all the admitted neonates, glucose level was measured within $1 \mathrm{~h}$ of NICU admission from capillary blood by a heel prick after adequate warming of the foot, using the "Accu-Chek Active" blood glucose meter (Roche, Switzerland) whose readings automatically display plasma glucose levels. The reading range of this blood glucose meter is from 10 to $600 \mathrm{mg} / \mathrm{dL}$.

Hyperglycemia was defined as a plasma glucose $>145$ $\mathrm{mg} / \mathrm{dL}$ [7]. We considered a glucose level of $146-180$ as "mild hyperglycemia" and a glucose level over $180 \mathrm{mg} / \mathrm{dL}$ as "moderate/severe hyperglycemia." On the other hand, hypoglycemia was defined, according to the Pediatric Endocrinology Society guidelines [17], as a plasma glucose level $\leq 50 \mathrm{mg} / \mathrm{dL}$ in the first $48 \mathrm{~h}$ of life or $\leq 60 \mathrm{mg} / \mathrm{dL}$ beyond that age.

For each patient, a complete diagnostic workup was performed, including complete blood count (CBC), CRP, and arterial blood gas, in addition to liver and kidney function tests. Microbiological cultures, including blood,
CSF, and urine, were withdrawn upon admission. CSF analysis and culture were performed if early-onset or late-onset sepsis were strongly suspected unless lumbar puncture was contraindicated, e.g., if the patient was clinically unstable. Isolates which could be either pathogenic or contaminant, such as coagulase-negative staphylococci and Streptococcus viridans, needed a repeat culture from a separate bleed (not from an indwelling catheter) to confirm their pathogenic nature but this was not done in all cases.

Patients were closely monitored over the disease course. The primary outcome was the NICU mortality. Infants who died in NICU were called "non-survivors," while those discharged home were called "survivors."

\section{Statistical method}

Qualitative variables were presented as numbers and percentages. Normally distributed continuous variables were presented as the mean \pm standard deviation and compared using the $t$ test (for two variables) or "analysis of variance" (ANOVA) [for more than two variables]. Non-normally distributed continuous variables were expressed as the median (minimum-maximum) and compared using the Mann-Whitney $U$ test (for two variables) or Kruskal-Wallis test (for three variables). To assess the associations between categorical variables, the chi-squared $\left(x^{2}\right)$ test was used while Fisher exact test was used when more than $25 \%$ of the cells had expected counts less than 5 . Univariate logistic regression analysis was used to test the association of variables with mortality. Multivariate logistic regression analysis was used to adjust for confounding variables. Logistic regression analysis yields an odds ratio. If the odds ratio is greater than 1 , this means that individuals exposed to a certain variable have a greater risk of developing an outcome (e.g., mortality) compared with those not exposed to the same variable (positive association). The larger the odds ratio, the greater the risk of developing the outcome. On the other hand, an odds ratio below 1 means that individuals exposed to a variable have a lower risk of developing the outcome compared with those not exposed (negative association).

All tests were bilateral, and a $P$ value of less than 0.05 was considered statistically significant. The statistical calculations were performed using the IBM Statistical Package for the Social Sciences version 20 (SPSS, Inc., Chicago, IL, USA).

\section{Results}

\section{Characteristics of the study population}

The study included 174 infants with neonatal sepsis. Their basic characteristics are shown in Table 1 . The mortality rate was $22.4 \%$. Sepsis was culture proven in 73 infants (42\%). The isolated pathogens included Klebsiella, Staphylococcus aureus, Pseudomonas aeruginosa, Candida, Escherichia coli, and Acinetobacter. 
Table 1 Demographic, clinical, and laboratory characteristics of patients

\begin{tabular}{|c|c|c|c|c|}
\hline Characteristic & Survivors $(n=135)$ & Non-survivors $(n=39)$ & All patients $(n=174)$ & $P$ value \\
\hline Postnatal age, days & $7(1-27)$ & $11(1-27)$ & $8(1-27)$ & $0.001^{*}$ \\
\hline Female sex & $62(45.9 \%)$ & $16(41 \%)$ & $78(45 \%)$ & 0.59 \\
\hline Weight, kg & $2.73 \pm 0.58$ & $2.46 \pm 0.71$ & $2.66 \pm 0.62$ & $0.022^{*}$ \\
\hline Gestational age, week & $38(35-40)$ & $37(35-42)$ & $37.5(35-42)$ & 0.25 \\
\hline Preterm & $34(25.2 \%)$ & $15(38.5 \%)$ & 49 (28.2\%) & 0.1 \\
\hline Full term & $101(74.8 \%)$ & $24(61.5 \%)$ & $125(71.8 \%)$ & \\
\hline Cesarean delivery & $108(80 \%)$ & $33(84.6 \%)$ & $141(81 \%)$ & 0.52 \\
\hline Early-onset sepsis & $37(27.4 \%)$ & $8(20.5 \%)$ & $45(25.8 \%)$ & 0.39 \\
\hline Late-onset sepsis & $98(72.6 \%)$ & $31(79.5 \%)$ & $129(74.1 \%)$ & \\
\hline Proven sepsis & 47 (34.8\%) & $26(66.7 \%)$ & $73(42 \%)$ & $<0.001^{*}$ \\
\hline Possible sepsis & $88(65.2 \%)$ & $13(33.3)$ & $101(58 \%)$ & \\
\hline Invasive mechanical ventilation & $76(56.3 \%)$ & $35(89.7 \%)$ & $111(63.8 \%)$ & $<0.001^{*}$ \\
\hline Type of organism & & & & 0.48 \\
\hline Gram positive & $14(10.4 \%)$ & $5(12.8 \%)$ & 19 (10.9\%) & \\
\hline Gram negative & $29(21.5 \%)$ & $17(43.6 \%)$ & $46(26.4 \%)$ & \\
\hline Candida & $4(3 \%)$ & $4(10.3 \%)$ & $8(4.6 \%)$ & \\
\hline Glycemic status & & & & $0.024^{*}$ \\
\hline High & $14(10.4 \%)$ & $8(20.5 \%)$ & $22(12.6 \%)$ & \\
\hline Low & $10(7.4 \%)$ & $9(23.1 \%)$ & 19 (10.9\%) & \\
\hline Normal & $111(82.2 \%)$ & $22(56.4 \%)$ & $133(76.4 \%)$ & \\
\hline $\mathrm{CRP}, \mathrm{mg} / \mathrm{dL}$ & $27(0-289)$ & $77(2-316)$ & $47(0-316)$ & $0.015^{*}$ \\
\hline WBC $(\times 1000 / \mathrm{mL})$ & $12.9(2.7-51)$ & $11.5(2.7-50)$ & $12.6(2.7-51)$ & 0.32 \\
\hline Platelets (× 1000/mL) & $162(5-648)$ & $40(4-676)$ & $141(4-676)$ & $<0.001^{*}$ \\
\hline Hemoglobin, g/dL & $12.84 \pm 3.11$ & $11.73 \pm 2.51$ & $12.6 \pm 3.01$ & $0.042^{*}$ \\
\hline Creatinine, mg/dL & $0.6(0.2-2.7)$ & $0.6(0.16-1.2)$ & $0.6(0.16-2.7)$ & 0.89 \\
\hline
\end{tabular}

Data is presented as number (percentage), mean \pm standard deviation, or median (minimum-maximum)

CRP C-reactive protein, WBC white blood cell count.

*Statistically significant

\section{Prevalence of glucose level abnormalities}

The median plasma glucose level of patients was $91 \mathrm{mg} /$ dL (range $17-315 \mathrm{mg} / \mathrm{dL}$ ). $23.6 \%$ of infants had abnormalities in glucose level upon admission. Hyperglycemia occurred in $12.6 \%$, while hypoglycemia occurred in $10.9 \%$ of the study population (Table 1).

\section{Relation of the glycemic status to the patients' characteristics}

Table 2 shows the relation of glycemic status to the patients' demographic, clinical, and laboratory data. The platelet count differed according to the glycemic status $(P=$ 0.015). The median platelet count was significantly lower among infants with hypoglycemia compared with those having normoglycemia. There was also a significant difference in WBC count according to the glycemic status $(P=$ 0.029). The median WBC count was significantly lower among the hypoglycemia subgroup compared with both the normoglycemia and the hyperglycemia subgroups.
Relation of the glycemic status to morbidity

A significant difference was found among the three patient subgroups as regards the mechanical ventilation rate (Table 2). Mechanical ventilation rate was significantly higher among patients with hypoglycemia compared with those having hyperglycemia and those with normoglycemia $(P=0.046)$. There was no significant difference in mechanical ventilation rate between patients with hyperglycemia and those with normoglycemia.

On the other hand, no significant difference was found in the length of NICU stay or serum creatinine according to the glycemic status (Table 2).

\section{Relation of the glycemic status to mortality}

The distribution of glucose abnormalities among survivors and non-survivors is shown in Table 1 . In addition, Table 2 shows a significantly higher mortality rate in both the hypoglycemia and the hyperglycemia subgroups compared with the normoglycemia subgroup $(P=0.002)$. 
Table 2 Relation of the glycemic status to mortality and other patient characteristics

\begin{tabular}{|c|c|c|c|c|}
\hline Patients' characteristics & Hyperglycemia $(n=22)$ & Hypoglycemia $(n=19)$ & Normoglycemia $(n=133)$ & $P$ value \\
\hline Mortality & $8(36.4 \%)$ & $9(47.4 \%)$ & $22(16.5 \%)$ & $0.002^{*}$ \\
\hline Postnatal age, days & $10(1-27)$ & $9.5(3-24)$ & $7(1-27)$ & 0.32 \\
\hline Female sex & $11(50 \%)$ & $12(63.2 \%)$ & 55 (41.4\%) & 0.17 \\
\hline Weight, kg & $2.6 \pm 0.89$ & $2.44 \pm 0.69$ & $2.68 \pm 0.54$ & 0.15 \\
\hline Gestational age, week & $37(35-40)$ & $37(35-39)$ & $38(35-42)$ & 0.37 \\
\hline Cesarean delivery & $18(81.8 \%)$ & $16(84.2 \%)$ & $107(80.5 \%)$ & 0.92 \\
\hline Early-onset sepsis & $7(31.8 \%)$ & $3(15.8 \%)$ & $35(26.3 \%)$ & 0.49 \\
\hline Late-onset sepsis & $15(68.2 \%)$ & $16(84.2 \%)$ & $98(73.7 \%)$ & \\
\hline Proven sepsis & $7(31.8 \%)$ & $10(52.6 \%)$ & $56(42.1 \%)$ & 0.4 \\
\hline Possible sepsis & $15(68.2 \%)$ & $9(47.4 \%)$ & 77 (57.9\%) & \\
\hline Invasive MV & $13(59.1 \%)$ & $17(89.5 \%)$ & $81(60.1 \%)$ & $0.046^{*}$ \\
\hline Length of $\mathrm{NICU}^{\mathrm{a}}$, days & $25(10-97)$ & $20(5-70)$ & $18(2-98)$ & 0.19 \\
\hline Platelets, 1000/mL & $98(6-483)$ & $38(4-401)$ & $156(5-648)$ & $0.015^{*}$ \\
\hline WBC, $1000 / \mathrm{mL}$ & $16.7(2.7-50)$ & $9.9(3.9-27.7)$ & $13(2.7-51)$ & $0.029^{*}$ \\
\hline Hemoglobin, g/dL & $12.04 \pm 3.61$ & $11.56 \pm 2.85$ & $12.79 \pm 2.93$ & 0.056 \\
\hline $\mathrm{CRP}, \mathrm{mg} / \mathrm{dL}$ & $48(3-200)$ & $65.5(4-213)$ & $32.5(0-316)$ & 0.2 \\
\hline Serum creatinine, mg/dL & $0.54(0.3-1.2)$ & $0.5(0.3-1.2)$ & $0.6(0.16-2.7)$ & 0.84 \\
\hline
\end{tabular}

Data is expressed as number (\%), mean $\pm \mathrm{SD}$, or median (maximum-minimum)

MV mechanical ventilation, NICU neonatal intensive care unit, CRP C-reactive protein, WBC white blood cell count *Statistically significant

aLength of hospital stay among survivors

Univariate logistic regression analysis for prediction of mortality yielded an odds ratio greater than 1 for both hyperglycemia and hypoglycemia (Table 3), signifying that the presence of either hyperglycemia or hypoglycemia increases the risk of death. This association of hyperglycemia and hypoglycemia with mortality remained significant after adjustment for weight and postnatal age in the multivariate model.

No significant difference in mortality rate was detected between infants with mild hyperglycemia and those having normoglycemia whereas the mortality rate among infants with moderate/severe hyperglycemia was significantly higher compared with those having normoglycemia (Table 4).

\section{Discussion}

In the present study, abnormalities in the admission plasma glucose level were not uncommon in infants with neonatal sepsis which lends support to the routine practice of measuring glucose level to these infants upon NICU admission.

Unlike hypoglycemia, which is a well-known manifestation of neonatal sepsis, hyperglycemia has received much less attention. However, in one study, hyperglycemia was reported among $24.6 \%$ of infants admitted into NICU, with sepsis accounting for $78.8 \%$ of hyperglycemia cases, but no data was given about the specific prevalence of hyperglycemia among infants with sepsis [18].

In another study, $6.9 \%$ of infants with neonatal sepsis had a blood glucose level over $200 \mathrm{mg} / \mathrm{dL}$ whereas $9.9 \%$ had a glucose level under $40 \mathrm{mg} / \mathrm{dL}$ [19]. The lower frequency of glucose abnormalities in the latter study, compared with ours, might be related to differences in the definitions of hypoglycemia and hyperglycemia or to a

Table 3 Univariate and multivariate logistic regression analysis for prediction of mortality by the glycemic status

\begin{tabular}{|c|c|c|c|c|}
\hline \multirow[t]{2}{*}{ Variable } & \multicolumn{2}{|l|}{ Univariate analysis } & \multicolumn{2}{|l|}{ Multivariate analysis } \\
\hline & OR $(95 \% \mathrm{Cl})$ & $P$ value & Adjusted OR (95\% Cl) & $P$ value \\
\hline Hyperglycemia & $2.88(1.08-7.7)$ & $0.035^{*}$ & $2.89(1.03-8.13)$ & $0.043^{*}$ \\
\hline Hypoglycemia & $4.54(1.65-12.46)$ & $0.003^{*}$ & $3.86(1.32-11.26)$ & $0.014^{*}$ \\
\hline Weight & $0.49(0.26-0.91)$ & $0.024^{*}$ & $0.6(0.31-1.15)$ & 0.12 \\
\hline Postnatal age & $1.09(1.04-1.16)$ & $0.001^{*}$ & $1.09(1.03-1.16)$ & $0.003^{*}$ \\
\hline
\end{tabular}

$O R$ odds ratio, $C l$ confidence interval

*Statistically significant 
Table 4 The mortality rate according to the degree of hyperglycemia

\begin{tabular}{llllll}
\hline & Normoglycemia $(n=$ & $\begin{array}{l}\text { Mild hyperglycemia }(n= \\
7)\end{array}$ & $\begin{array}{l}P \\
\text { value }\end{array}$ & $\begin{array}{l}\text { Normoglycemia }(n= \\
133)\end{array}$ & $\begin{array}{l}\text { Moderate/severe hyperglycemia }(n=15) \\
133)\end{array}$ \\
\hline $\begin{array}{l}\text { Non- } \\
\text { survivors }\end{array}$ & $22(16.5 \%)$ & $2(28.6 \%)$ & 0.34 & $22(16.5 \%)$ & $6(40 \%)$ \\
Survivors & $111(83.5 \%)$ & $5(71.4 \%)$ & & $111(83.5 \%)$ & $9(60 \%)$ \\
\hline
\end{tabular}

*Statistically significant

discrepancy in gestational age which was, unfortunately, not reported by the latter study.

There is adequate awareness of the dangers of neonatal hypoglycemia which is routinely screened for and immediately treated among sick neonates since it is frequently associated with short-term and long-term serious clinical consequences. Furthermore, in an infant with a diagnosis of sepsis, some signs like lethargy, poor feeding, and apnea may be erroneously attributed to the sepsis process itself although they may be a manifestation of an associated unrecognized hypoglycemia which might itself be harmful if left untreated.

In contrast, hyperglycemia does not trigger a similar alarm response on the part of health care workers and is frequently left untreated because it is thought to produce no serious problems. However, our current findings do not support this practice as it turned out that the mortality rate among the hyperglycemic subgroup was significantly higher compared with that among the normoglycemic ones. Besides, hyperglycemia was an independent predictor of mortality with an odds ratio of 2.89 .

Previous studies of neonatal hyperglycemia predominantly targeted very premature infants, whether or not having sepsis, and demonstrated a clear association of hyperglycemia with mortality [12, 20, 21]. In contrast, there is a dearth of data concerning the impact of hyperglycemia on full-term and late-preterm neonates with sepsis. In the only report we were able to retrieve [19], septic neonates with an admission blood glucose level $>200 \mathrm{mg} / \mathrm{dL}$ and those with a level $<40 \mathrm{mg} / \mathrm{dL}$ had a significantly higher mortality rate compared with the other infants but the authors did not tell about the gestational age of their cohort.

As for morbidity, no association was found, in the present study, between hyperglycemia and the need for mechanical ventilation or the length of NICU stay, which is consistent with a previous study of extremely low birth weight (ELBW) infants [21] although another study of ELBW infants reported an association of hyperglycemia with the length of NICU stay [12].

The pathogenic effects of hyperglycemia could be mediated by increased oxidative stress or by a pro-inflammatory state resulting from the high glucose level. Furthermore, hyperglycemia possesses a pro-thrombotic effect and reduces endothelial nitric oxide, thus decreasing tissue perfusion [22]. Moreover, there are concerns about the potential deleterious consequences of hyperglycemia on the developing brain as indicated by clinical [20] and experimental [23] studies. The latter effects could be attributed to hyperglycemia-induced oxidative stress [24] which can, in turn, produce neuronal apoptosis [25].

An interesting finding in the present study was the observation of a significantly higher mortality rate among infants with moderate/severe hyperglycemia compared with those having normoglycemia. Meanwhile, no significant difference in mortality was found between infants with mild hyperglycemia and those with normoglycemia. These relations could signify, if confirmed in larger cohorts, that the upper safe limit of glucose concentration in neonatal sepsis might be closer to $180 \mathrm{mg} / \mathrm{dL}$ rather than $145 \mathrm{mg} /$ $\mathrm{dL}$. This is supported by recent meta-analyses of randomized controlled trials performed in critically ill pediatric patients which failed to demonstrate a survival benefit from tight glycemic control [26, 27]. Similarly, the most recent adult sepsis guidelines recommend treating hyperglycemia with insulin infusion only if two consecutive blood glucose levels are $>180 \mathrm{mg} / \mathrm{dL}$ [28]. Likewise, there has been a strong trend among neonatologists to define hyperglycemia as a blood glucose above $180 \mathrm{mg} / \mathrm{dL}$ [29].

It should be stressed that observational studies, including ours, are not sufficient alone to define the safe upper glucose level in neonates because it is quite possible that hyperglycemia might not be the cause of mortality and morbidity but just an epiphenomenon indicating that sepsis is severe. Undoubtedly, randomized controlled trials are needed to settle that issue. Another important point that needs to be taken into consideration is that tight glycemic control carries the risk of hypoglycemia as shown by recent meta-analyses [26, 27]. Regardless of this controversy, hyperglycemia appears to be useful for predicting mortality in neonatal sepsis.

Compared with hyperglycemia, hypoglycemia was found, in the present study, to have a more evident association with mortality (adjusted odds ratio $=3.86$ ). Moreover, infants with hypoglycemia were more likely to need invasive mechanical ventilation. In addition, hypoglycemia was associated with a significantly lower platelet count which is a prognostic marker in neonatal sepsis [30]. Although hypoglycemia might not be causally linked to these effects, our findings indicate that it is a good prognostic tool that should warn physicians of an unfavorable clinical outcome so that more close monitoring and aggressive treatment would be instituted. 
Noteworthy, the postnatal age was significantly higher among non-survivors which could be explained by the fact that a significant number of infants are referred to our NICU from other hospitals after a lag of several days when a place is available. This delay made the age of referred infants older and, meanwhile, might have contributed to their mortality.

There are several limitations of the present study. The sample sizes were not large enough to draw firm conclusions. In addition, we used a single glucose measurement upon NICU admission rather than the mean or peak levels over a prolonged period. However, a single measurement seems to be a simpler tool that can be readily utilized by physicians to predict the prognosis. Besides, we measured plasma glucose level by blood glucose meter whose results are not as reliable as those of formal laboratory testing. Finally, the observational nature of the present study cannot prove the causal relation of glucose abnormalities to mortality and morbidity. Randomized controlled trials are, therefore, certainly needed.

\section{Conclusion}

Abnormalities in plasma glucose level are common among full-term and late-preterm neonates with sepsis and can be used for prediction of prognosis. Both hyperglycemia and hypoglycemia were independently associated with mortality. Hypoglycemia was, in addition, associated with a higher rate of mechanical ventilation. However, it is not possible, based on the present study, to prove a causal link of glucose abnormalities to mortality and morbidity. Consequently, larger randomized controlled trials are required.

\section{Abbreviations}

ANOVA: Analysis of variance; CBC: Complete blood count; Cl: Confidence interval; CRP: C-reactive protein; CSF: Cerebrospinal fluid; ELBW: Extremely low birth weight; NICU: Neonatal intensive care unit; OR: Odds ratio

\section{Acknowledgements}

Not applicable

\section{Authors' contributions}

DME designed the study, evaluated the patients, and analyzed the data. MSE evaluated the patients, analyzed the data, and wrote the manuscript. Both authors read and approved the final manuscript.

\section{Funding}

This research did not receive any specific grant from funding agencies in the public, commercial, or not-for-profit sectors.

\section{Availability of data and materials}

Data sharing is not applicable to this article as no datasets were generated or analyzed during the current study.

\section{Ethics approval and consent to participate}

The study protocol was approved by the Menoufia Faculty of Medicine Committee for Medical Research Ethics.

Consent for publication

Not applicable

\section{Competing interests}

The authors declare that they have no competing interests.

Received: 4 June 2019 Accepted: 23 July 2019

Published online: 02 September 2019

\section{References}

1. Brocklehurst P, Farrell B, King A et al (2011) Treatment of neonatal sepsis with intravenous immune globulin. N Engl J Med 365:1201-1211

2. Ottolini MC, Lundgren K, Mirkinson L, Cason S, Ottolini MG (2003) Utility of complete blood count and blood culture screening to diagnose neonatal sepsis in the asymptomatic at risk newborn. Pediatr Infect Dis J 22:430-434

3. Manzoni P, Castagnola E, Mostert M, Sala U, Galletto P, Gomirato G (2006) Hyperglycaemia as a possible marker of invasive fungal infection in preterm neonates. Acta Paediatr 95(4):486-493

4. Cornblath M, Hawdon JM, Williams AF et al (2000) Controversies regarding definition of neonatal hypoglycemia: suggested operational thresholds. Pediatrics 105(5):1141-1145

5. Burns CM, Rutherford MA, Boardman JP, Cowan FM (2008) Patterns of cerebral injury and neurodevelopmental outcomes after symptomatic neonatal hypoglycemia. Pediatrics 122(1):65e74

6. Arhan E, Öztürk Z, Serdaroğlu A, Aydın K, Hirfanoğlu T, Akbaș Y (2017) Neonatal hypoglycemia: a wide range of electroclinical manifestations and seizure outcomes. Eur J Paediatr Neurol 21(5):738-744

7. Hemachandra AH, Cowett RM (1999) Neonatal hyperglycemia. NeoReviews 20(7):e16-e24

8. Mitanchez-Mokhtari D, Lahlou N, Kieffer F, Magny JF, Roger M, Voyer M (2004) Both relative insulin resistance and defective islet beta-cell processing of proinsulin are responsible for transient hyperglycemia in extremely preterm infants. Pediatrics 113:537-541

9. Limesand SW, Rozance PJ, Zerbe GO, Hutton JC, Hay WW Jr (2006) Attenuated insulin release and storage in fetal sheep pancreatic islets with intrauterine growth restriction. Endocrinology 147:1488-1497

10. Stark AR, Carlo WA, Tyson JE et al (2001) Adverse effects of early dexamethasone in extremely-low-birth-weight infants: National Institute of Child Health and Human Development Neonatal Research Network. N Engl J Med 344:95-101

11. Beardsall K, Vanhaesebrouck S, Ogilvy-Stuart AL et al (2010) Prevalence and determinants of hyperglycemia in very low birth weight infants: cohort analyses of the NIRTURE study. J. Pediatr 157(5):715-9.e1-3

12. Hays SP, Smith EO, Sunehag AL (2006) Hyperglycemia is a risk factor for early death and morbidity in extremely low birth-weight infants. Pediatrics 118:1811-1818

13. Auerbach A, Eventov-Friedman S, Arad I, Peleg O et al (2013) Long duration of hyperglycemia in the first 96 hours of life is associated with severe intraventricular hemorrhage in preterm infants. J Pediatr 163(2):388-393

14. Ertl T, Gyarmati J, Gaal V, Szabo I (2006) Relationship between hyperglycemia and retinopathy of prematurity in very low birth weight infants. Biol Neonate 89:56-59

15. Lean WL, Kamlin CO, Garland SM, Jacobs SE (2015) Stable rates of neonatal sepsis in a tertiary neonatal unit. J Paediatr Child Health 51:294-299

16. Poggi C, Bianconi T, Gozzini E, Generoso M, Dani C (2015) Presepsin for the detection of late onset sepsis in preterm newborns. Pediatrics 135:68-75

17. Thornton PS, Stanley CA, De Leon DD et al (2015) Recommendations from the Pediatric Endocrine Society for evaluation and management of persistent hypoglycemia in neonates, infants, and children. J Pediatr 167(2): 238-245

18. Mohammed MM, Abdel Rahman SM (2016) Frequency of neonatal hyperglycaemia at Gaafar Ibnauf Children's Hospital: clinical aspects and short term outcome. Sudan J Paediatr 16(1):45-52

19. Ahmad S, Khalid R (2012) Blood glucose levels in neonatal sepsis and probable sepsis and its association with mortality. J Coll Physicians Surg Pak 22(1):15-18

20. van der Lugt NM, Smits-Wintjens VE, van Zwieten PH, Walther FJ (2010) Short and long term outcome of neonatal hyperglycemia in very preterm infants: a retrospective follow-up study. BMC Pediatrics 10:52

21. Kao LS, Morris BH, Lally KP, Stewart CD, Huseby V, Kennedy KA (2006) Hyperglycemia and morbidity and mortality in extremely low birth weight infants. J Perinatol 26(12):730-736

22. Marik PE, Raghavan M (2004) Stress-hyperglycemia, insulin and immunomodulation in sepsis. Intensive Care Med 30:748-756 
23. Rosa AP, Mescka CP, Catarino FM et al (2018) Neonatal hyperglycemia induces cell death in the rat brain. Metab Brain Dis 33(1):333-342

24. Rosa AP, Jacques CE, de Souza LO et al (2015) Neonatal hyperglycemia induces oxidative stress in the rat brain: the role of pentose phosphate pathway enzymes and NADPH oxidase. Mol Cell Biochem 403(1-2):159-167

25. Yang CM, Lin CC, Hsieh HL (2017) High-glucose-derived oxidative stressdependent Heme Oxygenase-1 expression from astrocytes contributes to the neuronal apoptosis. Mol Neurobiol 54(1):470-483

26. Zhao Y, Wu Y, Xiang B. Tight glycemic control in critically III pediatric patients: A meta-analysis and systematic review of randomized controlled trials. Pediatr Res 2018. doi: https://doi.org/10.1038/pr.2017.310. [Epub ahead of print] Review

27. Chen L, Li T, Fang F, Zhang Y, Faramand A (2018) Tight glycemic control in critically ill pediatric patients: a systematic review and meta-analysis. Crit Care 22(1):57

28. Rhodes A, Evans LE, Alhazzani W et al (2017) Surviving sepsis campaign: international guidelines for management of sepsis and septic shock: 2016. Intensive Care Med 43(3):304-377

29. Alsweiler JM, Kuschel CA, Bloomfield FH (2007) Survey of the management of neonatal hyperglycaemia in Australasia. J Paediatr Child Health 43:632

30. Charoo BA, lqbal Jl, lqbal Q, Mushtaq S, Bhat AW, Nawaz I (2009) Nosocomial sepsis-induced late onset thrombocytopenia in a neonatal tertiary care unit a prospective study. Hematol Oncol Stem Cell Ther 2:349-353

\section{Publisher's Note}

Springer Nature remains neutral with regard to jurisdictional claims in published maps and institutional affiliations.

\section{Submit your manuscript to a SpringerOpen ${ }^{\circ}$ journal and benefit from:}

- Convenient online submission

- Rigorous peer review

- Open access: articles freely available online

- High visibility within the field

- Retaining the copyright to your article

Submit your next manuscript at $\boldsymbol{\nabla}$ springeropen.com 